\title{
Airborne Characterization of the Chemical, Optical, and Meteorological Properties, and Origins of a Combined Ozone-Haze Episode over the Eastern United States
}

\author{
BRETT F. TAUBMAN \\ Department of Chemistry, University of Maryland, College Park, College Park, Maryland \\ Lackson T. Marufu, Charles A. Piety, Bruce G. Doddridge, and Jeffrey W. Stehr \\ Department of Meteorology, University of Maryland, College Park, College Park, Maryland \\ RusSELl R. DicKeRson \\ Department of Chemistry, and Department of Meteorology, University of Maryland, College Park, College Park, Maryland
}

(Manuscript received 13 June 2003, in final form 25 November 2003)

\section{ABSTRACT}

\begin{abstract}
Airborne observations of trace gases, particle size distributions, and particle optical properties were made during a constant altitude transect from New Hampshire to Maryland on 14 August 2002, the final day of a multiday haze and ozone $\left(\mathrm{O}_{3}\right)$ episode over the Mid-Atlantic and northeastern United States. These observations, together with chemical, meteorological, and dynamical analyses, suggest that a simple two-reservoir model, composed of the lower free troposphere (LFT), where photochemical processes are accelerated and removal via deposition does not occur, and the planetary boundary layer (PBL), where most precursor species are injected, may realistically represent the physics and chemistry of severe, multiday haze and $\mathrm{O}_{3}$ episodes over the MidAtlantic and Northeast. Correlations among $\mathrm{O}_{3}$, potential temperature $(\theta)$, the scattering Angström exponent $(\alpha)$, and relative humidity $(\mathrm{RH})$ suggest that high concentrations of $\mathrm{O}_{3}$ and relatively large, internally mixed sulfate and black carbon (BC) particles were produced in the LFT. Conversely, the PBL contained less $\mathrm{O}_{3}$ and more externally mixed, primary sulfate and BC particles than the LFT. Backward trajectories indicate source regions in the Midwest and Mid-Atlantic urban corridor, with southerly transport up the urban corridor augmented by the Appalachian lee trough and nocturnal low-level jet.
\end{abstract}

\section{Introduction}

Variability in the concentrations of haze and ozone $\left(\mathrm{O}_{3}\right)$ in the lower atmosphere is controlled by local and regional emissions, synoptic and mesoscale meteorology, and boundary layer chemistry and dynamics. Yet some of these processes and their effects on air quality, particularly boundary layer dynamics and mesoscale meteorological phenomena, are not very well understood. The daytime mixed layer is known to be a reservoir of local emissions and regionally transported emissions that are entrained as it deepens (Berkowitz and Shaw 1997; Banta et al. 1998; Luke et al. 1998; Ryan et al. 1998; Zhang and Rao 1999; Baumann et al. 2000; Fast et al. 2002). The lower free troposphere (LFT) may also act as a reservoir of photochemically aged air parcels that are not subject to deposition, particularly during multiday stagnation events. This paper

Corresponding author address: Dr. Brett F. Taubman, Dept. of Chemistry, University of Maryland, College Park, 2107 Computer and Space Science Building, College Park, MD 20742.

E-mail: btaubman@atmos.umd.edu investigates the hypothesis that the chemistry and physics of multiday haze and $\mathrm{O}_{3}$ episodes over the MidAtlantic and northeastern United States may be treated as a simple two-reservoir model, comprising the LFT and planetary boundary layer (PBL). Conclusions are based on aircraft measurements made during a constant altitude transect from Manchester, New Hampshire $\left(42.9^{\circ} \mathrm{N}, 71.4^{\circ} \mathrm{W}\right)$, to College Park, Maryland $\left(39.0^{\circ} \mathrm{N}\right.$, $76.9^{\circ} \mathrm{W}$ ), on 14 August 2002, the last day of a multiday haze and $\mathrm{O}_{3}$ episode, and subsequent analyses of air parcel age, source apportionment, and boundary layer chemistry and dynamics.

Ozone formation in the troposphere occurs in the presence of carbon-containing species (represented here with the simplest atmospheric carbon-containing species, $\mathrm{CO}$ ), $\mathrm{NO}_{x}$, and sunlight via the following reaction pathway:

$$
\begin{aligned}
\mathrm{CO}+\mathrm{OH}\left(+\mathrm{O}_{2}\right) & \rightarrow \mathrm{CO}_{2}+\mathrm{HO}_{2}, \\
\mathrm{HO}_{2}+\mathrm{NO} & \rightarrow \mathrm{NO}_{2}+\mathrm{OH}, \\
\mathrm{NO}_{2}+h v & \rightarrow \mathrm{NO}+\mathrm{O},
\end{aligned}
$$




$$
\begin{aligned}
\mathrm{O}+\mathrm{O}_{2}+\mathrm{M} & \rightarrow \mathrm{O}_{3}+\mathrm{M}, \\
\mathrm{O}_{3}+h v & \rightarrow \mathrm{O}_{2}+\mathrm{O}\left({ }^{1} \mathrm{D}\right), \\
\mathrm{O}\left({ }^{1} \mathrm{D}\right)+\mathrm{H}_{2} \mathrm{O} & \rightarrow 2 \mathrm{OH},
\end{aligned}
$$

where $h v$ represents a photon, and $\mathrm{M}$ is a third body needed to stabilize the $\mathrm{O}_{3}$ molecule (typically either $\mathrm{N}_{2}$ or $\mathrm{O}_{2}$ ). Ozone may subsequently regenerate $\mathrm{NO}_{2}$ through reaction with NO:

$$
\mathrm{O}_{3}+\mathrm{NO} \rightarrow \mathrm{O}_{2}+\mathrm{NO}_{2} .
$$

Thus, concentrations of $\mathrm{O}_{3}$ are highly dependent upon $\mathrm{NO}_{x}$ concentrations (Crutzen 1971). When the sun goes down and $\mathrm{NO}_{2}$ cannot be photolyzed, $\mathrm{O}_{3}$ is no longer produced. Ozone captured in the stable nocturnal boundary layer is then destroyed through reaction with $\mathrm{NO}$ or surface deposition. The lifetime of this $\mathrm{O}_{3}$ is several hours. When $\mathrm{O}_{3}$ remains in the free troposphere, however, it is no longer subject to deposition and its lifetime may be as long as several weeks.

The synoptic meteorology associated with $\mathrm{O}_{3}$ episodes over the eastern United States has been investigated in a number of studies (Vukovitch 1995; Zelenka 1997; Ryan et al. 1998; Zhang et al. 1998; Kleinman et al. 2000; Seaman and Michelson 2000; Sistla et al. 2001; Rao et al. 2003) and is reasonably well understood. Regional high $\mathrm{O}_{3}$ events often occur when the Bermuda high strengthens and extends west into the eastern United States. Subsidence east of the ridge induces clear skies, high temperatures, atmospheric stability, and stagnant winds. These factors enhance photochemistry and inhibit vertical mixing, thereby contributing to increased local concentrations of $\mathrm{O}_{3}$. Circulation around the ridge results in westerly transport of $\mathrm{O}_{3}$ and $\mathrm{O}_{3}$ precursors from the Midwest to the eastern United States, where they combine with local emissions. In the eastern United States, hazy conditions often occur during periods of high $\mathrm{O}_{3}$, but not always (Chen 2002). The meteorological conditions that support high concentrations of regional particles with aerodynamic diameters $<2.5 \mu \mathrm{m}\left(\mathrm{PM}_{2.5}\right)$ are not as well characterized as for $\mathrm{O}_{3}$. However, recent studies have shown that transport of $\mathrm{PM}_{2.5}$ from the south and west into the region plays a role (Malm 1992; Chen et al. 2002; Civerolo et al. 2003).

Two mesoscale meteorological phenomena often associated with air pollution events in the eastern United States are the Appalachian lee trough (APLT) and the nocturnal low-level jet (LLJ). The synoptic flow typical during these events is orthogonal to the Appalachian mountain range. As the air descends over the eastern ridge of the mountains it is adiabatically heated, creating a column of hot air. In response to the increased buoyancy of the air parcel, surface pressures drop and a mesoscale trough forms (Seaman and Michelson 2000). To conserve absolute vorticity, the winds turn cyclonically across the trough. The APLT is associated with approximately $70 \%$ of the high $\mathrm{O}_{3}$ episodes in the MidAtlantic (Pagnotti 1987).

The LLJ in this region occurs between approximately 0000 and 0600 eastern standard time (EST) and is a south-southwesterly wind maximum in the residual layer, generally observed between $\sim 300$ and $1000 \mathrm{~m}$. The wind speeds are typically $\sim 10-20 \mathrm{~m} \mathrm{~s}^{-1}$ and are greater than those in the underlying nocturnal boundary layer and those just above the jet. The nocturnal boundary layer provides a low-friction surface over which the jet can travel. This phenomenon also seems to be orographically derived, possibly resulting from the differential heating and pressure gradients associated with sloping terrain (e.g., Parish et al. 1988). Pollutant transport via the LLJ is disproportionately important during periods of stagnation when geostrophic winds are light.

The chemical and optical properties of transported pollutants may be very different from those locally emitted. Air pollution originating in the Midwest is dominated by power plant emissions with high levels of $\mathrm{SO}_{2}$ (but not CO) that lead to secondary aerosol formation and a highly scattering, sulfate-dominated haze (Malm 1992). Sulfates are formed in the gas phase by means of the following reactions:

$$
\begin{aligned}
\mathrm{OH}+\mathrm{SO}_{2}+\mathrm{M} & \rightarrow \mathrm{HOSO}_{2}+\mathrm{M}, \\
\mathrm{HOSO}_{2}+\mathrm{O}_{2}+\mathrm{M} & \rightarrow \mathrm{HO}_{2}+\mathrm{SO}_{3}+\mathrm{M}, \text { and } \\
\mathrm{SO}_{3}+\mathrm{H}_{2} \mathrm{O} & \rightarrow \mathrm{H}_{2} \mathrm{SO}_{4},
\end{aligned}
$$

and in the aqueous phase through reaction with hydrogen peroxide:

$$
\mathrm{SO}_{2}+\mathrm{H}_{2} \mathrm{O}_{2} \rightarrow \mathrm{H}_{2} \mathrm{SO}_{4} \text {. }
$$

Under cloud-free conditions, the lifetime of $\mathrm{SO}_{2}$ is dependent upon the gas phase reaction with the $\mathrm{OH}$ radical and dry deposition. At typical atmospheric concentrations of $\mathrm{OH}$, the lifetime of $\mathrm{SO}_{2}$ is roughly 1 week. The dry deposition velocity of $\mathrm{SO}_{2}$ is $\sim 1 \mathrm{~cm} \mathrm{~s}^{-1}$, so in a 1-km-deep boundary layer, the lifetime due to dry deposition is only $\sim 1$ day. When $\mathrm{SO}_{2}$ is transported out of the boundary layer, however, dry deposition is no longer a factor.

Mobile sources, predominant in urban centers in the eastern United States, emit significantly more $\mathrm{CO}$ and black carbon (BC) than point sources (Chen et al. 2001). The lifetime of CO is on the order of several weeks and it is therefore considered a fairly stable tracer species, whereas the lifetime of $\mathrm{BC}$, as with other particulate species, is thought to depend on the frequency of precipitation. The type and degree of mixing between sulfate-dominated particles and $\mathrm{BC}$ particles determines the absorptive capacity of the mixture (Haywood and Boucher 2000; Jacobson 2000, 2001; Chung and Seinfeld 2002; Lesins et al. 2002).

Investigation of the aforementioned hypothesis begins with a brief meteorological analysis of the 3-day episode, including new data on the impact of the LLJ on Mid-Atlantic and Northeast haze and ozone episodes. 
(a)

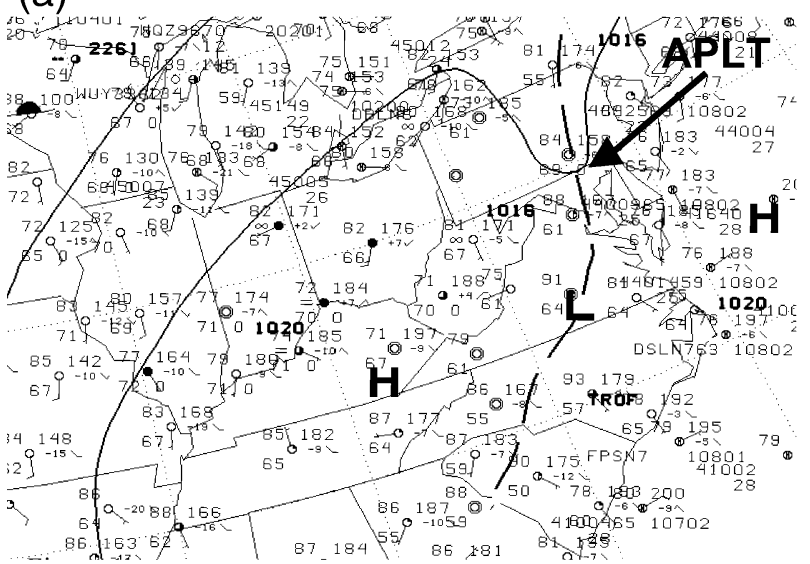

(b)

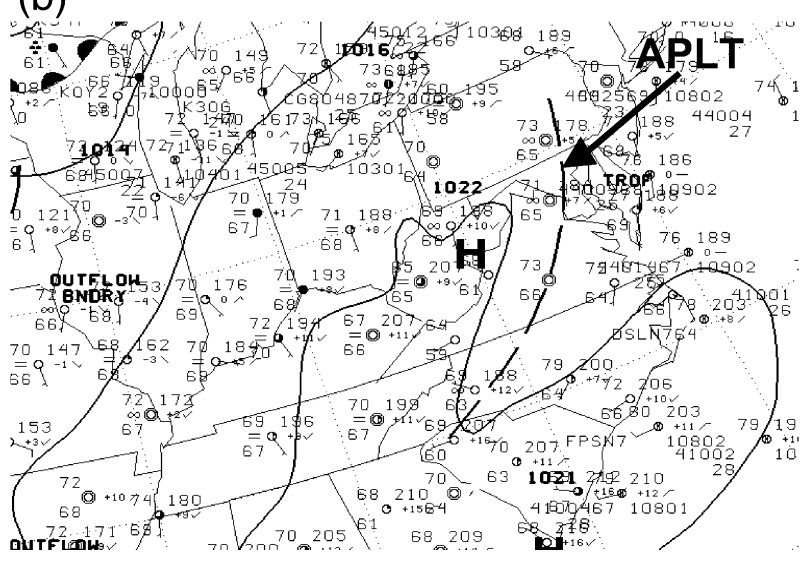

FIG. 1. NCEP surface analyses for (a) 0000 and (b) 1200 UTC 12 Aug 2002 that show a weak isobaric gradient normal to the U.S.Canadian border. The APLT is also labeled on the charts.

The research platform and sampling methodologies used in this study are then detailed. A statistical analysis is used in order to garner information about source apportionment and air parcel age. Potential temperature is used as a proxy for altitude above ground level to investigate the chemical and physical signatures of air parcels as they vary with height.

\section{Meteorology}

On 10 August 2002, a slow-moving upper-level ridge positioned itself over the Great Lakes, while a surface high pressure system lying below the region of convergence in the downwind upper-level trough blanketed the eastern seaboard. By 12 August at $850 \mathrm{mb}$, a trough over the Great Lakes, together with a ridge over the northeastern United States, created an isobaric gradient normal to an axis lying along the U.S.-Canadian border. Surface analyses on 12 August at 0000 UTC and 1200 UTC show a parallel, albeit weaker, isobaric pattern (Figs. 1a,b). This general pattern persisted through 14 August and resulted in prevailing southwesterly winds over the Midwest and Northeast. Stagnant conditions predominated over the Mid-Atlantic throughout the episode. Figures $1 \mathrm{a}$ and $1 \mathrm{~b}$ also indicate the presence of an APLT that augmented southerly flow up the urban corridor. Surface temperatures in the Mid-Atlantic and Northeast rose steadily between 10 and 14 August.

A LLJ was observed every morning between $\sim 0100$ UTC and 0700 UTC at Ft. Meade, Maryland, from 11 through 14 August (Fig. 2a). The wind speed maximum appears to be between $\sim 200$ and $800 \mathrm{~m}$ AGL, indicating that the nocturnal stable boundary layer was quite shallow, with a maximum depth of only $\sim 200 \mathrm{~m}$ AGL. The horizontal extent and magnitude of the jet on 12 August is shown in Fig. 2b, a time series plot of the Mid-Atlantic and Northeast generated using Rapid Update Cycle-2 (RUC-2) data (Benjamin et al. 1998). The wind vectors in both the observed and analysis data show southsouthwesterly flow during times of the jet maximum. At the indicated wind speeds and duration, an air parcel in the LLJ could travel $>200 \mathrm{~km}$ up the eastern seaboard overnight to mix with the local air under the jet once the nocturnal inversion eroded and vertical mixing ensued during the daytime.

\section{Sampling platform}

The sampling platform used for this study was a twinengine Piper Aztec-F PA-23-250 research aircraft. The aircraft is outfitted with a suite of trace gas and aerosol instruments, the inlets for which are engineered onto the upper fuselage. There is an aft-facing inlet plumbed to the trace gas instruments while a forward facing, isokinetic inlet feeds the aerosol instruments. Due to inlet sampling line losses of supermicrometer particles, all measurements reported are of submicrometer particles only. A meteorological probe is nestled between these two inlets. Position was measured and stored using a global positioning system (GPS; Garmin GPS-90), with 10-s resolution, and verified several times per flight relative to known geographic reference points. Temperature and relative humidity (RH) were measured using a thermistor and capacitive thin film, respectively, with a regularly calibrated Rustrak RR2-252 RH probe (EIL Instruments, Inc., Hunt Valley, Maryland). The instrument is capable of $0.5^{\circ} \mathrm{C}$ temperature precision and $2 \%$ humidity precision with a 10 -s response time. Pressure was measured using a Rosemount Model 2008 pressure transducer, capable of 5-mb precision, and calibrated regularly to a laboratory standard. Pressure altitude was calculated from static pressure using the U.S. Standard Atmosphere, 1976 (COESA 1976) approximation, normalized relative to known surface elevation and ambient surface static pressure averaged between takeoff and landing locations. A full description of the trace gas and aerosol instrument suite is given below.

Ozone data were acquired with a commercial instrument using ultraviolet (UV) absorption at $254 \mathrm{~nm}$ (Thermo Environmental, TEI Model 49, Franklin, Massa- 
chusetts), modified for increased (4 s) temporal response. This instrument was routinely compared to an in-house primary $\mathrm{O}_{3}$ calibrator (TEI Model 49PS) fed on zero-grade air.

For observations of $\mathrm{CO}$, a high-performance, modified (Dickerson and Delany 1988) commercial (TEI Model 48) nondispersive infrared gas filter correlation analyzer was used. For this study, the instrument had a detection limit of $\sim 24 \mathrm{ppbv}$ (signal-to-noise ratio $S: N$ $=1: 1$ for $\pm 2 \sigma$ noise) for a 1 -min mean of 10-s data, and was calibrated regularly using $\mathrm{CO}$ working standards (1-2-ppmv CO in nitrogen), in turn referenced to a National Institute of Standards and Technology (NIST) Standard Reference Material (9970 ppbv CO in nitrogen, certified; NIST, Gaithersburg, Maryland). This instrument is capable of $\sim 1 \%$ precision determined for a 1 -min mean of 10-s data. The CO instrument has undergone formal international calibrations (Novelli et al. 1998) under a World Meteorological Organization (WMO) protocol (Doddridge 1995).

A modified (Luke 1997), commercial, pulsed-fluorescence detector (TEI Model 43C) was used for measurements of ambient $\mathrm{SO}_{2}$. For this experiment, the $\mathrm{SO}_{2}$ instrument had a detection limit of $\sim 140$ parts per trillion by volume (pptv; $S: N=1: 1$ for $\pm 2 \sigma$ noise) for a 1 -min mean of 10 -s data and was calibrated regularly using $\mathrm{SO}_{2}$ working standards.
Information on the total number of particles with optical diameters between 0.01 and $1.0 \mu \mathrm{m}$ was obtained using a condensation particle counter (TSI Model 3007 $\mathrm{CPC}$ ). The concentration range of this instrument is 0 100000 particles per cubic centimeter. Number distributions for particles with optical diameters between 0.30 and $1.0 \mu \mathrm{m}$ (hereafter $\mathrm{nDp}$ ) were collected with an optical particle counter (Met One Model 9012) that used a laser-diode-based optical sensor to convert scattered light to numbers of particles per size range. The prespecified size ranges were $0.30-0.40,0.40-0.491$, $0.491-0.60,0.60-0.701,0.701-0.80$, and $0.80-1.0 \mu \mathrm{m}$.

Particle light absorption was measured using a Particle/Soot Absorption Photometer (PSAP; Radiance Research, Seattle, Washington), which quantified the intensity of 565-nm light after it passed through a filter on which ambient aerosol was deposited. A detection limit $(95 \%$ confidence level $)$ for $S: N=1$ is $0.9 \times$ $10^{-6} \mathrm{~m}^{-1}$ (Anderson et al. 1999; Bond et al. 1999) when 1 -min measurement averages are used as in this experiment.

The absorption measured at $565 \mathrm{~nm}$ was corrected for differences in flow rate (as measured by the instrument and an electronic bubble flowmeter) and spot size, instrumental variation, noise, and exaggerations of absorption due to scattering and nonscattering influences (Bond et al. 1999). These corrections resulted in a de-

(a)

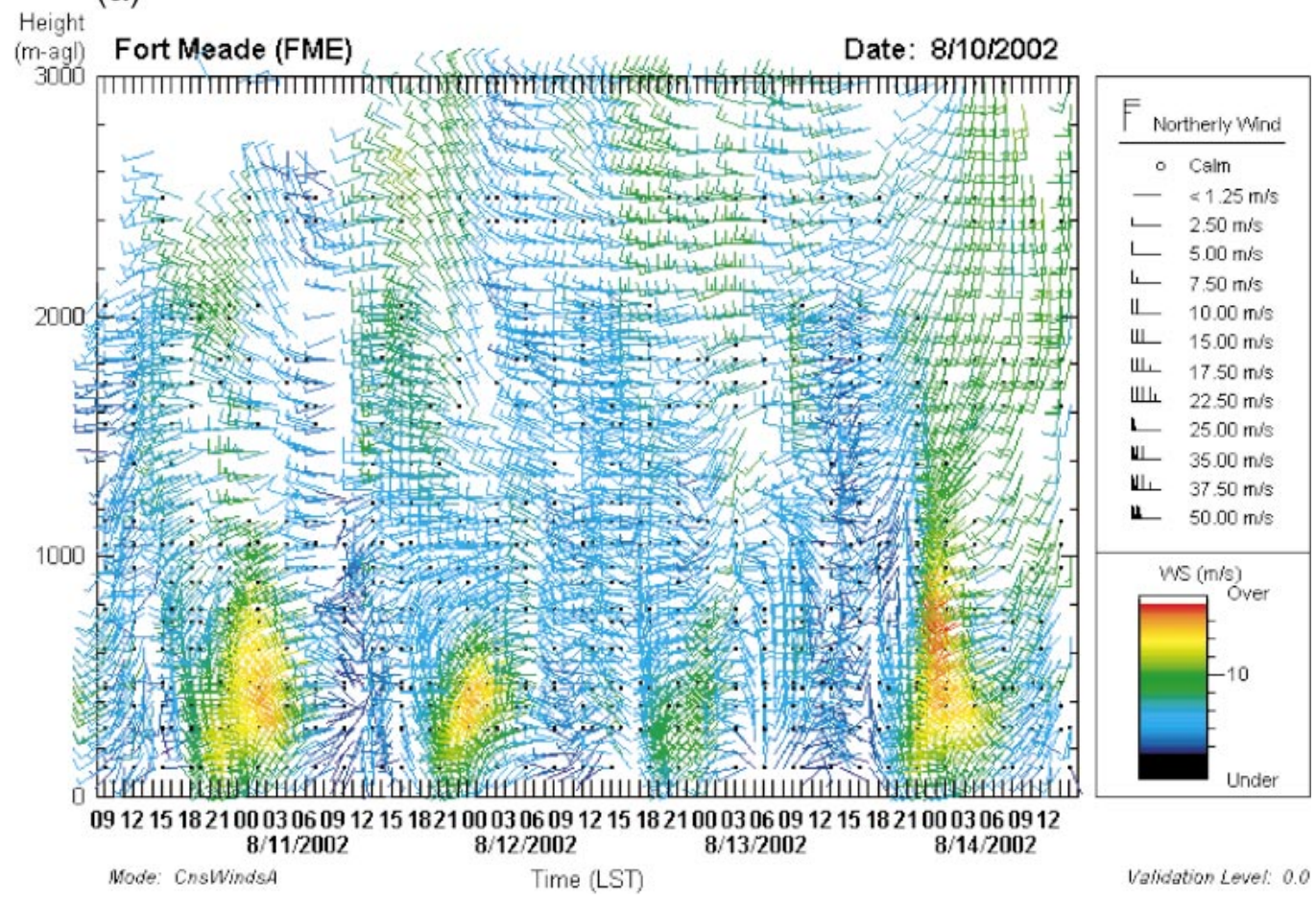

FIG. 2. (a) Wind profiler data (30-min average) from Ft. Meade, MD, from 0900 LT 10 Aug to 1500 LT 14 Aug 2002 and (b) a time series plot of the 950-mb (the approximate altitude of the LLJ) wind speed and direction over the Mid-Atlantic and Northeast from 0200 to 1100 UTC 12 Aug 2002 generated using RUC-2 data. The profiler data show a wind maximum between $\sim 200$ and $800 \mathrm{~m}$ AGL. Both plots show south-southwesterly flow in the jet. 
crease in absorption values from those indicated by the instrument from approximately $10 \%$ for the smaller values to almost $20 \%$ for the larger ones. The estimated instrumental uncertainty for the absorption values is $25 \%$ with $95 \%$ confidence.

The measured absorption was extrapolated from 565 to $550 \mathrm{~nm}$, based on the assumption that $\sigma_{\text {ap }} \propto 1 / \lambda$ (Bodhaine 1995; Hartley et al. 2000; Bergstrom et al.
2002), for calculation of the single scattering albedo at this wavelength (section 4d). Although it has been shown that large variations in $\mathrm{RH}$ can cause inaccuracies in absorption measurements made by the PSAP (Anderson et al. 2003), this was a constant altitude transect where the ambient RH fluctuated between $\sim 40 \%$ and $60 \%$. So, humidity effects on absorption measurements were presumed to be minimal. (b) $950 \mathrm{mb}$ wind $(\mathrm{m} / \mathrm{s})$ 08/12/02 02UTC

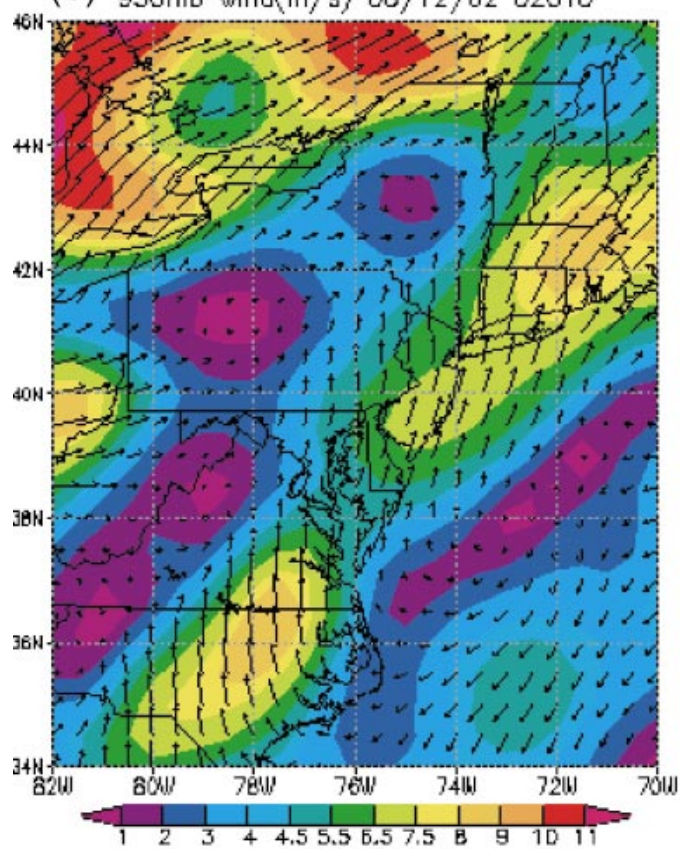

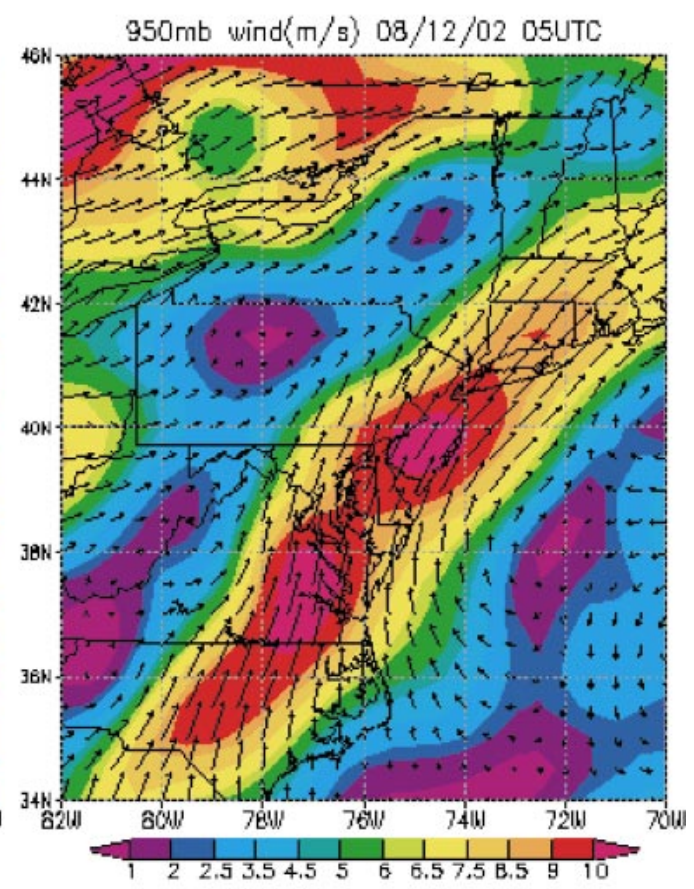

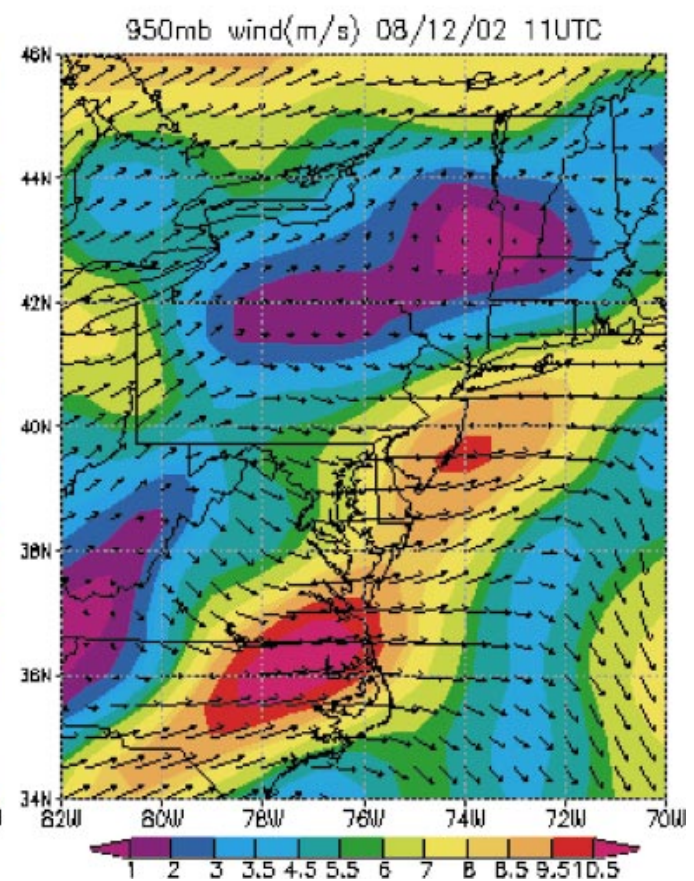

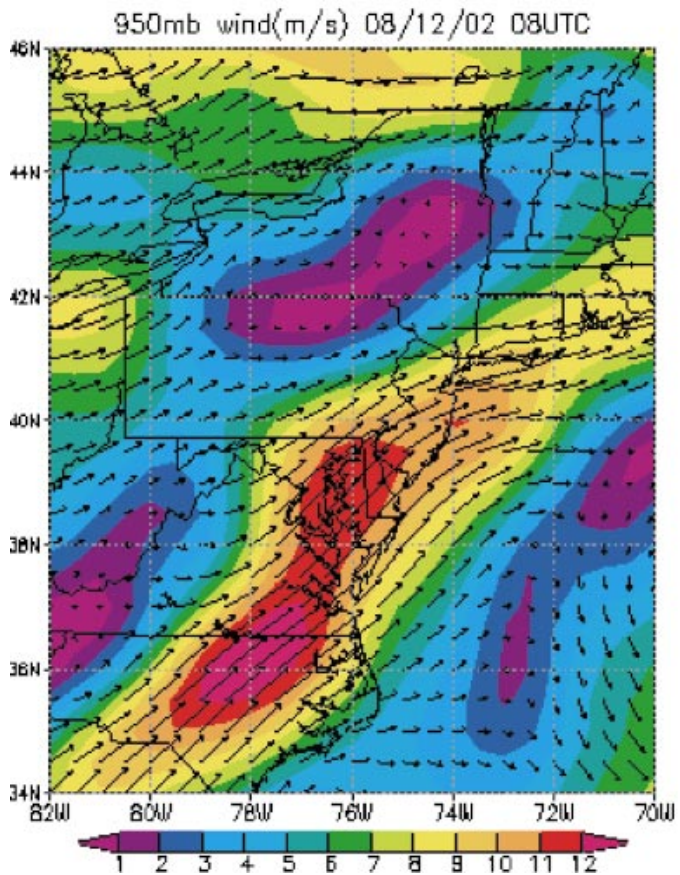

FIG. 2. (Continued) 
Particle light scattering was quantified using an integrating nephelometer (TSI Model 3563) that measured the total scattering coefficient at 450,550, and $700 \mathrm{~nm}$ (Anderson et al. 1996). The nephelometer was calibrated with $\mathrm{CO}_{2}$ and particle-free air, and corrected as necessary. At an averaging time of $5 \mathrm{~min}$, detection limits for $S: N=2$ are $\sigma_{\mathrm{sp}} 450=0.44 \times 10^{-6} \mathrm{~m}^{-1}, \sigma_{\mathrm{sp}} 550=$ $0.17 \times 10^{-6} \mathrm{~m}^{-1}$, and $\sigma_{\mathrm{sp}} 700=0.26 \times 10^{-6} \mathrm{~m}^{-1}$.

Corrections were also made to the measurements of total light scattering to account for forward-scattering angular truncation and nonlambertian distribution of illumination intensity. A wavelength-dependent correction factor $\left(C_{\mathrm{ts}}\right)$ was calculated assuming a linear relationship between $C_{\mathrm{ts}}$ and the Angström exponent $(\alpha)$, such that $C_{\mathrm{ts}}=a+b \alpha$, where $a$ and $b$ are constants used for submicrometer particles, and $\alpha_{450 / 550}, \alpha_{450 / 700}$, and $\alpha_{550 / 700}$ are used for 450,550 , and $700 \mathrm{~nm}$, respectively (Anderson and Ogren 1998). Application of the correction increased the scattering values at $550 \mathrm{~nm}$ by $\sim 7 \%$. The estimated instrumental uncertainty for values of total scattering is $10 \%$ with $95 \%$ confidence.

Measurements of light scattering were made after the sample airflow was dried from ambient conditions to an $\mathrm{RH}$ of $<20 \%$. This necessitated the estimation of a growth factor $F(\mathrm{RH})$ to account for hygroscopic particle growth. Growth factor $F(\mathrm{RH})$ is the ratio of ambient light scattering $(\lambda, \mathrm{RH})$ to dry light scattering $\sigma_{\mathrm{sp}}(\mathrm{ref})$ :

$$
F(\mathrm{RH})=\frac{\sigma_{\mathrm{sp}}(\lambda, \mathrm{RH})}{\sigma_{\mathrm{sp}}(\mathrm{ref})} .
$$

Factor $F(\mathrm{RH})$ was calculated using the following relationship between particle scattering coefficients at two values of RH:

$$
\frac{\sigma_{\mathrm{sp}}(\lambda, \mathrm{RH})}{\sigma_{\mathrm{sp}}(\mathrm{ref})}=\left(\frac{1-\mathrm{RH}_{\mathrm{amb}}}{1-\mathrm{RH}_{\mathrm{ref}}}\right)^{-\gamma},
$$

where $\mathrm{RH}_{\text {amb }}$ is the ambient $\mathrm{RH}, \mathrm{RH}_{\text {ref }}$ is the $\mathrm{RH}$ inside the nephelometer, and $\gamma$ is an empirically derived constant. Parallel nephelometers were not used in this study, so $\gamma$ had to be estimated. In polluted conditions, such as those on the East Coast, typical values of $\gamma$ range from $0.20-0.50$. For this study, a value of 0.35 was chosen as per Remer et al. (1997) due to the similarities of both the sampling platforms and the regions of the studies.

\section{Observations and analyses}

The flight began in Manchester, New Hampshire, at 2145:02 UTC on 14 August 2002 and ended in College Park, Maryland, at 0030:23 UTC, just after sunset (Fig. 3 ). An altitude of $800 \mathrm{~m}$ above mean sea level (MSL) was attained at 2150:41 UTC and maintained until 0020:00 UTC. Takeoff and landing are excluded from all time series plots for clarity.

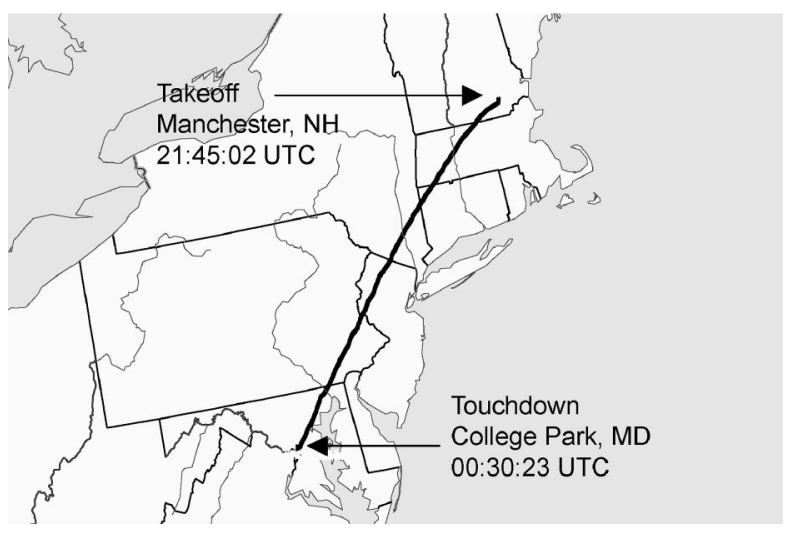

FIG. 3. Flight track that began in Manchester, NH, at 2145:02 UTC and ended in College Park, MD, at 0030:23 UTC. Except for initial ascent and final descent, the altitude was constant at $800 \mathrm{~m}$ above mean sea level.

\section{a. Trajectory analysis}

A backward-trajectory analysis of the entire flight track was performed utilizing the National Oceanic and Atmospheric Administration (NOAA) Air Resources Laboratory (ARL) Hybrid Single-Particle Lagrangian Integrated Trajectory (HYSPLIT) model (version 4; Draxler and Rolph 2003) and Eta Data Assimilation System (EDAS) meteorological fields (with a 3-h temporal resolution). The 72-h model vertical velocity backward trajectories ending at 500, 1000, and $1500 \mathrm{~m}$ AGL came primarily from the south-southwest and intersected many of the urban centers in the Mid-Atlantic and northeastern United States (e.g., Fig. 4). There was little difference in the source regions or transport direction of the parcels analyzed. However, a significant difference was seen in the vertical motions of the air parcels that culminated in southern upstate New York near the Hudson River valley (Fig. 4). A transition from downward vertical motion to upward vertical motion in this area appears to have occurred at $\sim 2300$ UTC.

\section{b. Correlations among trace gases}

Correlations among the chemical and physical properties observed during the flight allow for insight into source apportionment, photochemical age, and the dynamical structure of the lower atmosphere. Autocorrelation tests were performed by correlating measured variables with themselves over successive time intervals to estimate the number of independent air parcels (i.e., the number of degrees of freedom associated with each time series plot). The threshold for autocorrelation (nonrandomness between the two points) was $r>0.50$ (95\% confidence). Any value below this threshold indicated that there was no statistically significant relationship between the points after this time lag, thereby suggesting the presence of a discrete air parcel. The number of independent air parcels was then calculated from dividing the sampling period by the autocorrelated time lag. 
(a)

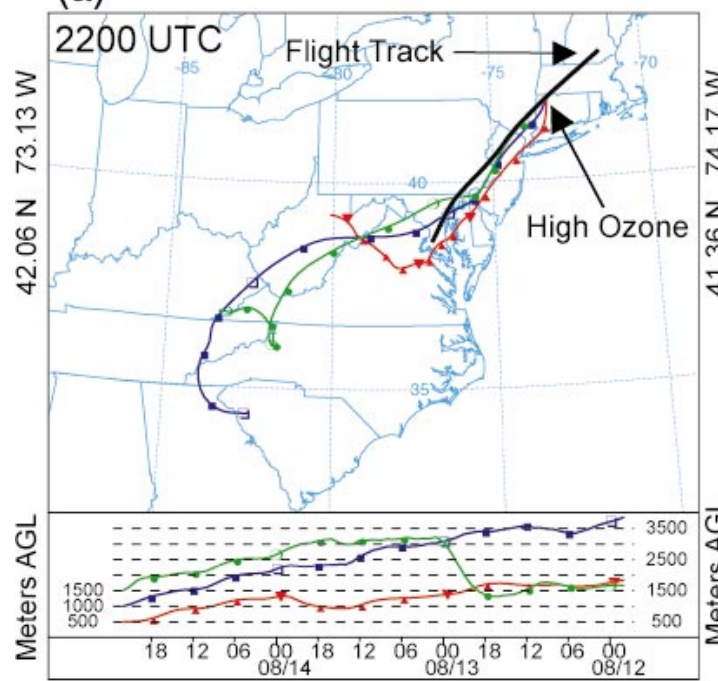

(b)

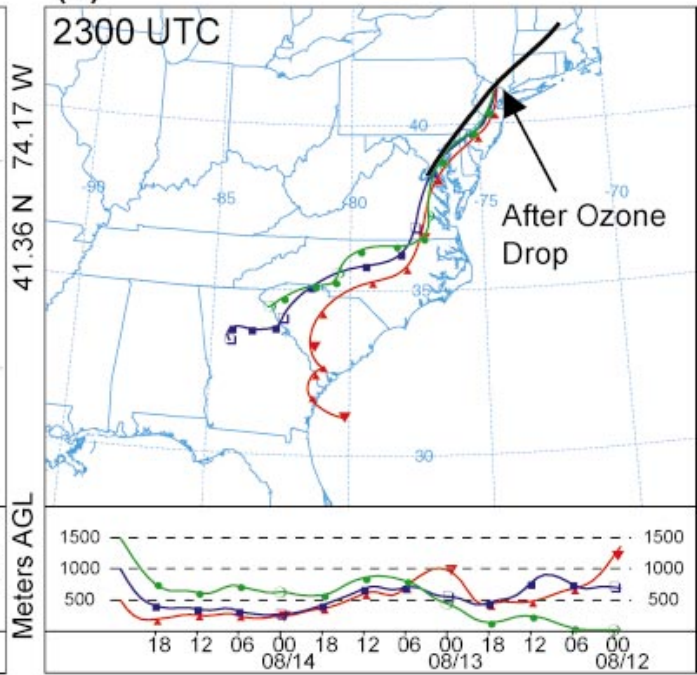

FIG. 4. Sample NOAA ARL EDAS model vertical velocity 72-h backward trajectories for air parcels at 500, 1000 , and $1500 \mathrm{~m} \mathrm{AGL}$ on 14 Aug 2002 at (a) $42.06^{\circ} \mathrm{N}, 73.13^{\circ} \mathrm{W}, 2200 \mathrm{UTC}$, where the highest $\mathrm{O}_{3}$ was measured, and (b) $41.36^{\circ} \mathrm{N}, 74.17^{\circ} \mathrm{W}, 2300 \mathrm{UTC}$ after a steep decline in $\mathrm{O}_{3}$ concentration. There is no noticeable distinction in transport direction between the trajectories in (a) and (b), but there is a manifest conversion from subsidence in (a) to upward vertical motion in (b).

Approximately 10 discrete air parcels were positively identified in this manner (the exact value varied slightly according to the variable tested). The statistical significance of each correlation was determined according to the number of degrees of freedom (discrete air parcels) and reported along with the correlation coefficients (Table 1).

Carbon monoxide and $\mathrm{SO}_{2}$ were positively correlated throughout the flight and early positive correlations were found between $\mathrm{O}_{3}$ and $\mathrm{CO}$ and $\mathrm{O}_{3}$ and $\mathrm{SO}_{2}$ (Table 1, Fig. 5 ), suggestive of a combination of mobile and pointsource emissions. The initial correlation between $\mathrm{O}_{3}$ and $\mathrm{CO}$ had a regression slope $\left(\Delta \mathrm{O}_{3} / \Delta \mathrm{CO}\right)$ of $0.31 \pm 0.04$. This value agrees with previous examples of polluted, North American, boundary layer air (Chin et al. 1994; Daum et al. 1996; Dickerson et al. 1995). Carbon mon-

TABLE 1. Correlation coefficients $r$ for trace gases, meteorological and dynamic parameters, and particle properties. The number in parentheses is the $p$ value (the probability that the statistical relationship occurred by random chance) for the regression. If two sets of correlation coefficients and $p$ values are given, the top one is for the regression until 2256:00 UTC and the bottom is for the period between 2256:10 and 2310:00 UTC.

\begin{tabular}{|c|c|c|c|c|c|}
\hline & $\mathrm{O}_{3}(\mathrm{ppbv})$ & CO (ppbv) & $\sigma_{\text {sp } 450}\left(\mathrm{~m}^{-1}\right)$ & $\sigma_{\text {ap }}\left(\mathrm{Mm}^{-1}\right)$ & $\alpha_{450 / 700}$ \\
\hline $\mathrm{CO}$ (ppbv) & $\begin{array}{r}0.70(0.08) \\
-0.84(0.02)\end{array}$ & & & & \\
\hline $\mathrm{SO}_{2}(\mathrm{ppbv})$ & $\begin{array}{r}0.70(0.08) \\
-0.67(0.10)\end{array}$ & $0.71(0.02)$ & & & \\
\hline$\sigma_{\mathrm{sp} 450}\left(\mathrm{~m}^{-1}\right)$ & $0.90(0.00)$ & & & & \\
\hline$\sigma_{\mathrm{sp} 550}\left(\mathrm{~m}^{-1}\right)$ & $0.89(0.00)$ & & & $\begin{array}{l}0.79(0.03) \\
0.10(0.87)\end{array}$ & \\
\hline $\begin{array}{l}\sigma_{\text {sp700 }}\left(\mathrm{m}^{-1}\right) \\
\mathrm{nDp}\left(\mathrm{dm}^{-3}\right)\end{array}$ & $0.88(0.00)$ & & & & \\
\hline $\begin{array}{l}\mathrm{nDp}\left(\mathrm{dm}^{-3}\right) \\
0.30-0.40 \mu \mathrm{m}\end{array}$ & $0.76(0.01)$ & & & $\begin{array}{r}0.50(0.25) \\
-0.45(0.31)\end{array}$ & \\
\hline $\begin{array}{l}\mathrm{nDp}\left(\mathrm{dm}^{-3}\right) \\
0.40-0.49 \mu \mathrm{m}\end{array}$ & $0.90(0.00)$ & & $0.96(0.00)$ & & \\
\hline $\mathrm{TPC}\left(\mathrm{cm}^{-3}\right)$ & $\begin{array}{r}0.67(0.10) \\
-0.63(0.13)\end{array}$ & & & $0.79(0.00)$ & \\
\hline$\sigma_{\text {ap }}\left(\mathrm{Mm}^{-1}\right)$ & $\begin{array}{r}0.68(0.09) \\
-0.73(0.16)\end{array}$ & & & & \\
\hline RH (\%) & & & & & $0.82(0.00)$ \\
\hline$\theta(\mathrm{K})$ & $0.56(0.09)$ & & & & $-0.86(0.00)$ \\
\hline $\begin{array}{l}\mathrm{BC}\left(\mu \mathrm{g} \mathrm{m}^{-3}\right) \\
\omega_{o}\end{array}$ & $\begin{array}{r}-0.58(0.17) \\
0.77(0.04)\end{array}$ & $0.57(0.09)$ & & & \\
\hline
\end{tabular}


(a)

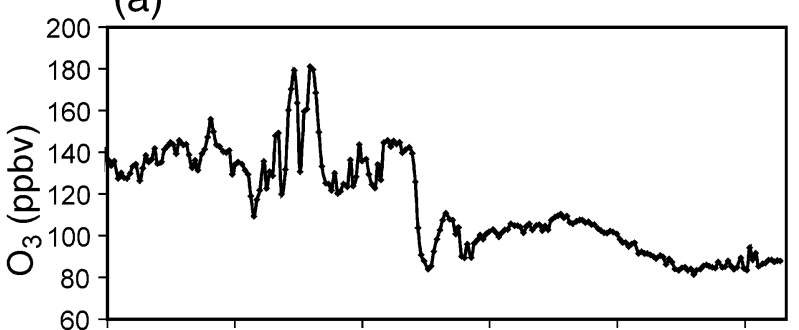

(b)

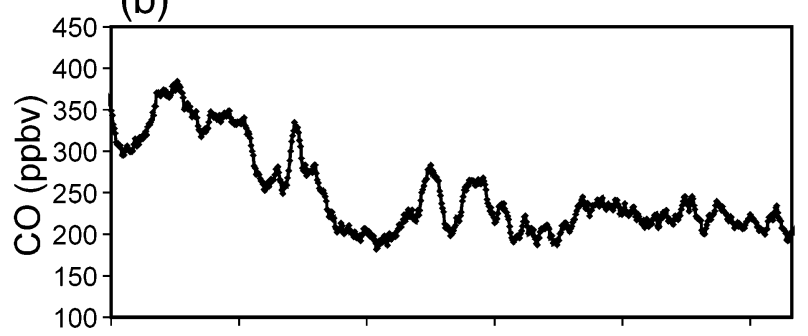

(c)

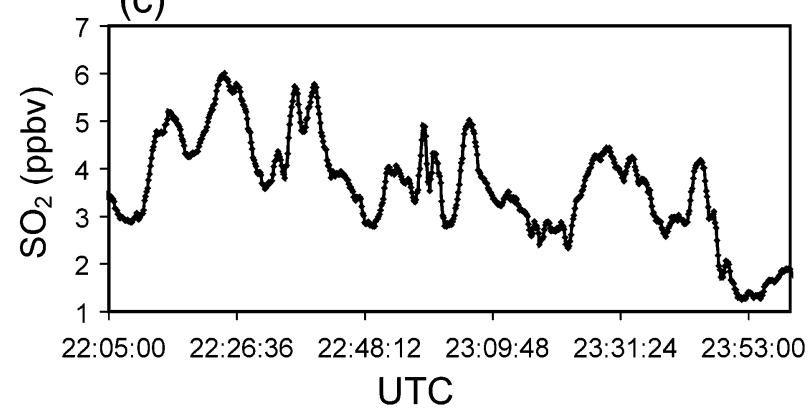

FIG. 5. (a) Ten-second ozone mixing ratios, (b) running 1-min mean $\mathrm{CO}$, and (c) $\mathrm{SO}_{2}$ mixing ratios measured during the flight. oxide fell off at $\sim 2240: 00$ UTC and no longer showed a strong positive correlation with $\mathrm{O}_{3}$ (Table 1, Fig. 5), whereas $\mathrm{SO}_{2}$ remained positively correlated with $\mathrm{O}_{3}$ until $\mathrm{O}_{3}$ declined at $\sim 2256: 00$ UTC (Table 1, Fig. 5). This suggests a shift from mixed mobile and point-source influences to point-source-dominated ones.

When the $\mathrm{O}_{3}$ concentration decreased at $\sim 2256: 00$ UTC near the Hudson River valley, $\mathrm{CO}$ and $\mathrm{SO}_{2}$ concentrations increased and became anticorrelated with $\mathrm{O}_{3}$ (Table 1, Fig. 5). This transition corresponds to the shift in the backward trajectories from downward to upward vertical motion. The increase in $\mathrm{CO}$ and $\mathrm{SO}_{2}$ suggests the influence of mixed sources again, while the sudden decrease in $\mathrm{O}_{3}$ could be explained by $\mathrm{NO}_{x}$ titration in the middle of a combination mobile and point-source plume.

\section{c. Correlations among trace gases and aerosol properties}

Ozone and $\mathrm{nDp}$ (especially particles with diameters between $0.40-0.491 \mu \mathrm{m}$ ), as well as $\mathrm{O}_{3}$ and $\sigma_{\mathrm{sp}}$, were positively correlated throughout the entire flight (Table 1, Figs. 5 and 6). Ozone and total particle count (TPC) between $10 \mathrm{~nm}$ and $\mu \mathrm{m}$ along with $\mathrm{O}_{3}$ and $\sigma_{\text {ap }}$ were initially positively correlated (Table 1, Figs. 5 and 6). However, these profiles became anticorrelated at $\sim 2256: 00$ UTC, when the $\mathrm{O}_{3}$ concentration succinctly declined (Table 1, Figs. 5 and 6). Thus, $\mathrm{O}_{3}$ remained correlated with particles between $\sim 0.30$ and $1 \mu \mathrm{m}$ in diameter, but when the $\mathrm{O}_{3}, \mathrm{nDp}$, and $\sigma_{\mathrm{sp}}$ profiles decreased at $\sim 2256: 00$ UTC, there was a significant increase in the number of absorptive particles $<0.30 \mu \mathrm{m}$ in diameter. This is evidence of primary $\mathrm{BC}$ particles emitted from a local, mobile source that had not had (a)
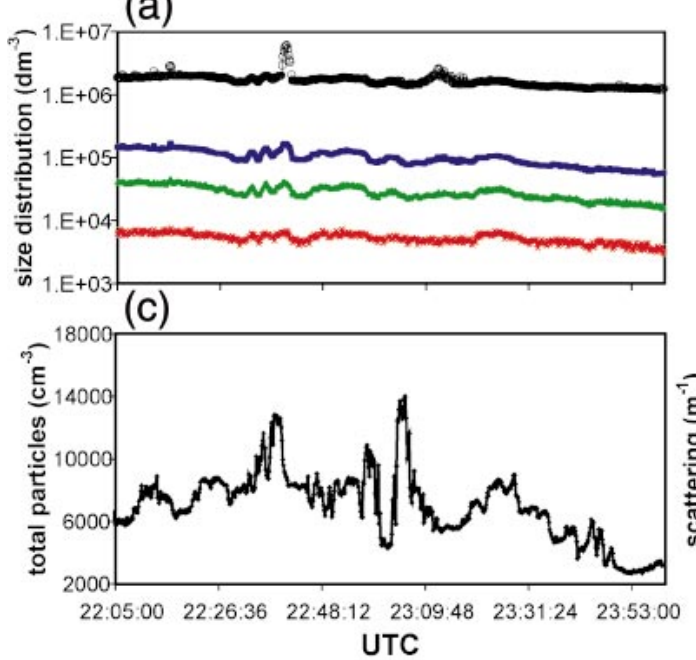

(b)

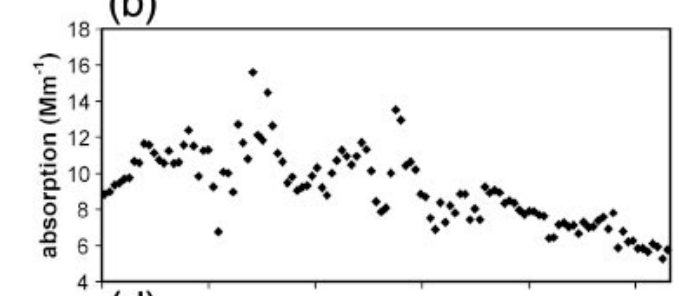

(d)

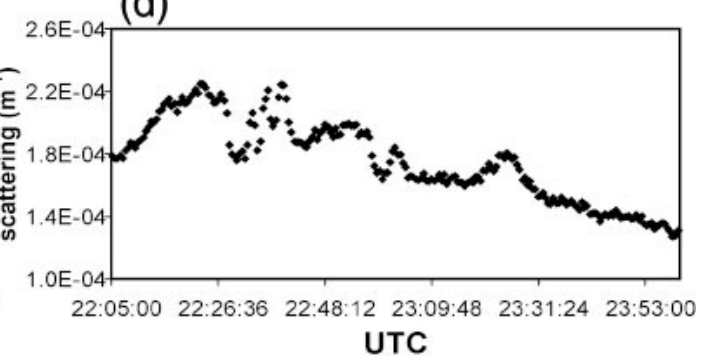

FIG. 6. (a) Particle size number distributions measured during the flight for the following size ranges: $0.30-0.40$ (black), 0.40-0.491 (blue), 0.491-0.60 (green), and 0.60-0.701 (red) $\mu \mathrm{m}$. (b) The $\sigma_{\text {ap }}$ corrected to $550 \mathrm{~nm}$, (c) total submicrometer particle count, and (d) $\sigma_{\mathrm{sp}}$ at $550 \mathrm{~nm}$ all measured during the flight. 


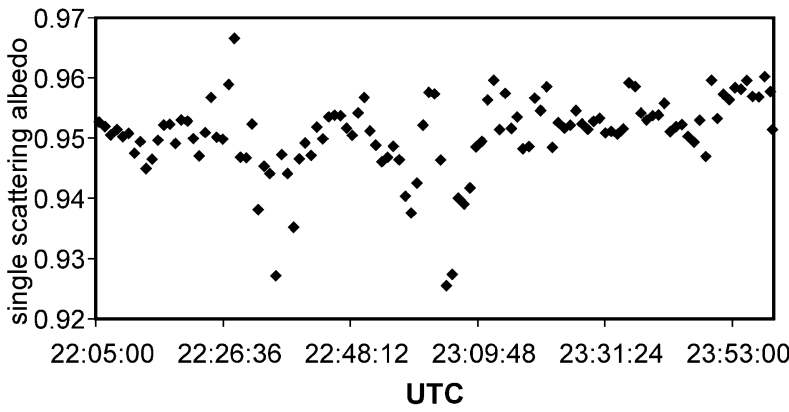

FIG. 7. Aerosol single scattering albedo $\omega_{o}$ at $550 \mathrm{~nm}$, calculated from flight data. The mean value for the flight was $0.95 \pm 0.01$.

sufficient time to mix with the sulfate-dominated haze of the region. When $\mathrm{nDp}, \sigma_{\mathrm{sp}}$, and $\sigma_{\mathrm{ap}}$ were correlated (before 2256:00 UTC), greater absorption occurred despite the presence of fewer total submicrometer particles. Assuming that the air parcels contained internally mixed $\mathrm{BC}$ and sulfate particles at that time, this suggests that the internal mixture was more absorptive than the external one.

The BC concentration was calculated from $\sigma_{\text {ap }}$ assuming BC is the primary absorber in atmospheric aerosols. Despite apparent differences in degrees of mixing, an average BC mass absorption efficiency of $7 \mathrm{~m}^{2} \mathrm{~g}^{-1}$ was assumed in accordance with prior regional surface and aircraft studies (Novakov et al. 1997; Chen et al. 2001). A regression analysis of $\mathrm{BC}$ and $\mathrm{CO}$ was performed and a correlation $(r=0.57)$ was found between the two (Table 1), with a slope of $\Delta \mathrm{BC} / \Delta \mathrm{CO}=0.0034$ \pm 0.0007. Chen et al. (2001) found a similar value $(0.0034 \pm 0.0013)$ for the annual average at Fort Meade, Maryland. They scaled this number by the North American $\mathrm{CO}$ emissions value to compute a $\mathrm{BC}$ emission rate of $0.32 \mathrm{Tg} \mathrm{yr}^{-1}$. The results of this flight support that estimate.

\section{d. Single scattering albedo}

Particle scattering is represented by the single scattering albedo $\left(\omega_{o}\right)$, the ratio of the particle scattering coefficient $\left(\sigma_{\mathrm{sp}}\right)$ to the extinction coefficient (the sum of the particle absorption coefficient $\sigma_{\mathrm{ap}}$ and $\sigma_{\mathrm{sp}}$ ):

$$
\omega_{o}=\frac{\sigma_{\mathrm{sp}}}{\left(\sigma_{\mathrm{sp}}+\sigma_{\mathrm{ap}}\right)} .
$$

Equation (3) represents the probability that a photon encountering the particle will be scattered. The aerosols measured during the flight were largely scattering. The mean value for $\omega_{o}$ at $550 \mathrm{~nm}$ over the entire flight was $0.95 \pm 0.01$ (see Fig. 7), in agreement with previous aircraft observations over the East Coast of the United States (e.g., Hartley et al. 2000; Hegg et al. 1997) and the Aerosol Robotics Network (AERONET) observations at the National Aeronautics and Space Administration (NASA) Goddard Space Flight Center between

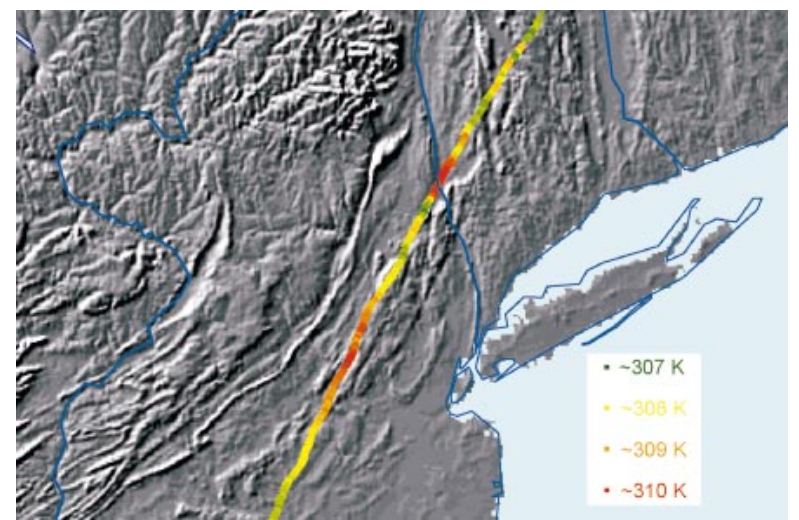

FIG. 8. Potential temperature $(\theta)$ plotted with color-coded values (provided in the key) along a portion of the flight track. These values are overlaid on a shaded relief digital elevation model of the northeastern United States. Darker shading signifies lower elevations, and lighter shading, higher elevations. The blue lines indicate rivers; the one in the middle is the Hudson River. This region shows the most obvious inverse relationship between $\theta$ and surface elevation.

1993 and $2000\left(\omega_{o}\right.$ at 440 and $670 \mathrm{~nm}$ equal to $0.98 \pm$ 0.02 and $0.97 \pm 0.02$, respectively; Dubovik et al. 2002). Nevertheless, the variations in $\omega_{o}$ were driven by the absorption in this study since $\sigma_{\mathrm{sp}}$ varied by as much as a factor of 3 , while $\sigma_{\mathrm{sp}}$ never varied by even a factor of 2 .

Before $\sim 2256: 00$ UTC, $\omega_{o}$ was anticorrelated to $\mathrm{O}_{3}$, while after this time, $\mathrm{O}_{3}$ and $\omega_{o}$ positively correlated (Table 1). Thus, initially, absorption was highest when the $\mathrm{O}_{3}$ mixing ratio was highest. Total scattering also peaked at this time, but absorption was relatively stronger, leading to a smaller $\omega_{o}$. After $\sim 2256: 00$ UTC, the greatest absorption was observed with the least $\mathrm{O}_{3}$. There was a large influx of small, absorptive particles during this time, and since $\sigma_{\mathrm{sp}}$ dropped off with $\mathrm{O}_{3}, \omega_{o}$ decreased accordingly.

\section{e. Thermodynamic analysis}

The flight under investigation was conducted at a constant altitude above mean sea level. Thus, the elevation above the surface increased or decreased according to the local terrain. Because the dynamic structure of the lower atmosphere must follow the surface features, the flight continually traversed through different dynamic altitudes. To investigate the dynamical structure of the lower atmosphere and the associated chemistry and physics, the potential temperature $(\theta)$ was calculated from the flight measurements of temperature and pressure. Figure 8 shows an inverse relationship between $\theta$, calculated along a portion of the flight path, and the surface elevation, generated using a digital elevation model. This is the expected result in a stable lower atmosphere, where $\theta$ is at a minimum and relatively constant in the daytime mixed layer, with a steep, positive gradient in the interfacial layer, and a smaller positive gradient in the LFT. Thus, as the surface elevation 
(a)
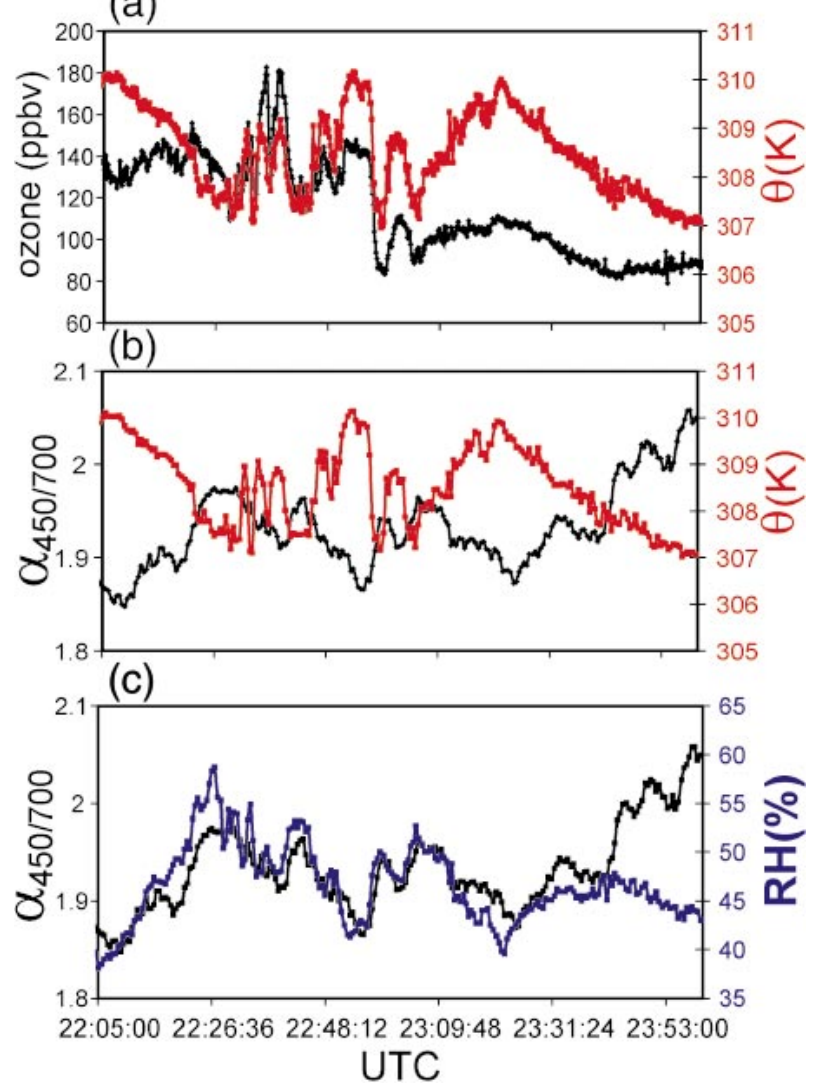

FIG. 9. (a) Ten-second $\mathrm{O}_{3}$ mixing ratios (black) recorded during the flight and potential temperature $\theta$ (red) derived from flight data; (b) $\theta$ (red) and $\alpha$ (black) calculated from flight data; and (c) $\mathrm{RH}$ (blue) and scattering Ångström exponent $\alpha$ (black) calculated from the ratio of total particle scattering, 450/700 (in $\mathrm{nm}$ ), measured during the flight.

decreases, flight elevation above ground level increases, as does $\theta$ if the altitude is at or above the interfacial layer.

It follows, then, that the chemical and physical nature of the atmosphere should vary with altitude, particularly between the PBL and the LFT. To investigate this hypothesis, statistical analyses with $\theta$ and representative chemical and physical values were performed. Ozone and $\theta$ were positively correlated throughout the flight (Fig. 9a, Table 1). Because $\theta$ is constant and at a minimum in the mixed layer, any increase would indicate a transition into the interfacial layer and beyond into the LFT. Likewise, $\mathrm{O}_{3}$ concentrations should be fairly constant in the mixed layer, and because of the positive correlation with $\theta$, any increases indicate more $\mathrm{O}_{3}$ in the LFT relative to the PBL. Exceptions to this rule result from the spatially and temporally dynamic nature of the atmosphere and the platform, but the consistency of the correlation supports the argument.

The age and degree of mixing of aerosol particles not only affects the optical properties of the particle, but also the size, which in turn affects the optical properties.
The scattering Ångström exponent $(\alpha)$ is a measure of the wavelength dependence of the scattering coefficient and is inversely related to the size of the particles:

$$
\alpha=\frac{-\log \left(\sigma_{\mathrm{sp} \lambda 1} / \sigma_{\mathrm{sp \lambda} 2}\right)}{\log \left(\lambda_{1} / \lambda_{2}\right)} .
$$

Throughout the flight, $\alpha$ was positively correlated with RH and anticorrelated with $\theta$ (Figs. 9b,c; Table 1). Within an individual air parcel, $\alpha$ and RH would be expected to anticorrelate because of the covariance of particle size and RH. Thus, the correlation between RH and $\alpha$ was due to the observation of distinct air parcels at discrete altitudes above the surface that contained particles of different sizes and unique optical properties. It can be reasonably assumed that particles in the LFT, where RH was lower and $\theta$ was higher, were more aged than those in the PBL. The photochemical processing of these particles would, therefore, be enhanced because of longer lifetimes, as well as increased actinic flux in the LFT. This would explain why, despite the lower RH, the particles in the LFT were larger than those in the PBL. Conversely, particles in the PBL, where RH was higher and $\theta$ was lower, were relatively fresher and less subject to photochemical processing and hence, were smaller.

\section{Discussion}

The thermodynamic analysis indicates that the observed chemical and optical properties varied according to altitude, specifically whether the observations were made in the PBL or the LFT. Drier, more aged air parcels were observed in the LFT where the protracted lower atmospheric stability allowed them to persist for multiple days without being subjected to vertical mixing, dilution, and deposition. These air parcels were more photochemically processed and contained higher concentrations of $\mathrm{O}_{3}$ and larger particles that scattered and absorbed visible light efficiently. The relatively fresh parcels in the PBL had less $\mathrm{O}_{3}$ and smaller particles that scattered light less efficiently, but were highly absorptive. Variations in the concentrations of $\mathrm{CO}$ and $\mathrm{SO}_{2}$ seemed to vary less according to altitude per se. Rather, the source region and photochemical age of the air parcels in which they resided played the more important role.

The change in vertical winds between the trajectories shown in Fig. 4 could be the result of upsloping winds on the windward side of the western ridge of the Hudson River valley. The associated shift from positive to negative correlations between several species of interest is likely due to observations of the difference between air with more regional characteristics above the LFT to more local air in the PBL. As mentioned before, the absolute accuracy of such a conclusion is questionable because of the spatially and temporally dynamic nature of the study. The fact that the study was performed in the late afternoon, however, reduces the incidence of thermally driven convective eddies. Turbulent eddies 


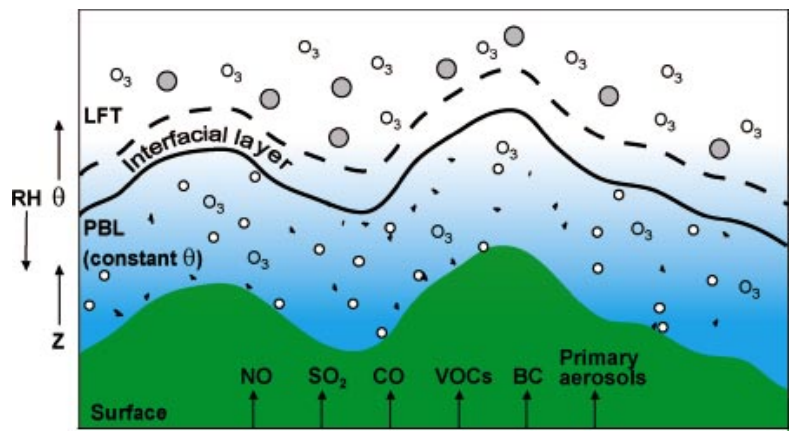

FIG. 10. A schematic of the two-reservoir system during the daytime. The vertical and horizontal axes represent altitude and distance, respectively. The shape of the inversion layer that delineates the PBL from the LFT mimics the variations in surface elevation (green). The inversion layer is shown here with an interfacial layer of finite thickness. The upward arrows with the chemical species along the surface represent the injection of emissions into the PBL. The blue-to-white gradient represents greater $\mathrm{RH}$ in the PBL relative to the LFT. Potential temperature $(\theta)$ is shown as constant in the mixed layer and increasing with altitude from the interfacial layer. The small white circles and black flecks in the PBL represent sulfate particles and BC particles, respectively. They are shown as an external mixture in the PBL. The larger gray circles in the LFT represent internally mixed sulfate and $\mathrm{BC}$ particles. The $\mathrm{O}_{3}$ represents molecules of ozone. There are more particles in the PBL than the LFT, but more molecules of ozone in the LFT.

would add to the variations in $\theta$, according to the associated heat flux, but would be on a much smaller scale than $\theta$ fluctuations due to terrain characteristics.

The current foci of numerical model simulations of severe air pollution episodes are on the composition of the lower atmosphere, including especially the structure of the inversion layer, and the chemical and physical processes that drive the events. This study provides a characterization of the chemistry and physics that occur during multiday episodes in the Mid-Atlantic and Northeast that should prove useful in these simulations. The chemical and physical structure of the lower atmosphere could be conceptualized as a simple, two-reservoir model, comprising the PBL and LFT (Fig. 10). Of particular importance is the realization that the LFT does not contain clean, background air during these episodes. This not only has direct consequences on model simulations of these episodes, but may have indirect ones as well. Photochemical mechanisms are accelerated in the LFT, but these mechanisms are also operating on air parcels with different chemical and physical characteristics than those in the PBL. Therefore, modeled photochemical mechanisms that work in the PBL would not be appropriate for the LFT. Numerical model simulations of multiday haze and ozone episodes over the Mid-Atlantic and Northeast must account for the unique chemistry and physics of the two reservoirs. However, future aircraft studies that specifically investigate the small-scale dynamical processes that drive the mixing between the two reservoirs are still necessary. These studies will allow for the more accurate simulation of transfer across the boundary separating the PBL and LFT.
The observations reported herein may have broader implications as well. Absorbing aerosols heat the atmosphere and alter atmospheric stability (e.g., Park et al. 2001; Menon et al. 2002). During a stagnation event such as this one, when stable layers of air pollution have discrete aerosol optical properties, preexisting atmospheric stability may be augmented if more absorptive aerosol layers are juxtaposed above more scattering layers. This could in turn create a positive feedback loop, inhibiting vertical mixing and dilution and ultimately delaying the termination of the episode. Such a distribution of aerosol optical properties could also have a significant impact on the solar radiation budget and therefore the accuracy of climate modeling studies.

A specific question regarding absorbing aerosols is the nature and extent of mixing between $\mathrm{BC}$ and sulfate particles. Although the aerosols encountered during this study primarily scattered solar radiation, there were manifest fluctuations in their absorptive nature, reflected in the calculated values of $\omega_{o}$. Two noticeable deviations from the mostly invariant mean value of $\omega_{o}$ were during the periods of highest observed $\mathrm{O}_{3}$ concentrations (between $\sim 2230: 00$ and $\sim 2240: 00$ UTC) and lowest observed $\mathrm{O}_{3}$ concentrations (from $\sim 2256: 00$ to $\sim 2310: 00$ UTC). During these times, $\omega_{o}$ dropped to a minimum value of $\sim 0.92$, with a mean value of 0.94 . Given the analytical uncertainty, a value of 0.94 is not statistically different from the overall mean, but does indicate greater relative absorption at these times. During the period of highest $\mathrm{O}_{3}$, the drop in $\omega_{o}$ may be attributed to two factors: a greater degree of internal mixing between $\mathrm{BC}$ and sulfate particles due to the age and photochemical processing of the air parcels in question, and a larger influx of absorptive BC particles due to transport up the eastern seaboard urban corridor. The influence of the APLT and LLJ during this episode redirected the westerly synoptic flow in a more southerly direction during the day and evening, respectively. As a result, air that had been transported from the industrialized Midwest then mixed with the urban plumes of the eastern seaboard.

Another question of great scientific interest involves the mechanism and time scale for particle formation. The strong correlation between $\mathrm{O}_{3}$ and $\mathrm{nDp}$ may provide evidence for the link between $\mathrm{O}_{3}$ and secondary organic aerosol formation through the oxidation of hydrocarbons (Andreae and Crutzen 1997). Greater atmospheric oxidizing potential through increased concentrations of $\mathrm{OH}$ and $\mathrm{H}_{2} \mathrm{O}_{2}$ concomitantly with $\mathrm{O}_{3}$ would also lead to the production of $\mathrm{SO}_{4}^{2-}$ from $\mathrm{SO}_{2}$ and thereby secondary aerosol formation. Further explanation for the correlation may lie in the oxidation of $\mathrm{SO}_{2}$ by dissolved $\mathrm{O}_{3}$ (Hoffman 1986), but this is unlikely since there were few clouds during the episode and the acidity of MidAtlantic and Northeastern aerosols would inhibit such a reaction. The correlation between $\mathrm{O}_{3}$ and $\sigma_{\mathrm{sp}}$ is likely a secondary result of the $\mathrm{O}_{3}$ and $\mathrm{nDp}$ correlation since the particles with diameters commensurate to visible 
wavelengths scatter that light most efficiently. Although, highly scattering particles, such as the ones encountered in this study, also increase the flux of diffuse UV radiation and may, therefore, increase the photochemical production of $\mathrm{O}_{3}$ as well (Dickerson et al. 1997), especially in the LFT.

\section{Conclusions}

The salient discovery of this study is that the chemistry and physics of severe, multiday haze and ozone episodes over the Mid-Atlantic and northeastern United States may be simply and accurately represented by two reservoirs, comprising the PBL and LFT. These conclusions are drawn from observations during a constant altitude flight from Manchester, New Hampshire, to College Park, Maryland, on 14 August 2002, the last day of a multiday haze and ozone episode. Most precursor species are injected into the PBL, where surface deposition may occur. When these precursors escape into the LFT, however, deposition is no longer a factor, and chemical lifetimes are protracted. Photochemical processes are also accelerated in the LFT and air parcels age photochemically with greater rapidity. As a result, more $\mathrm{O}_{3}$ and larger particles that scattered visible light more efficiently were observed in the LFT than in the PBL. An accurate numerical model simulation of photochemical smog processes over the Mid-Atlantic and Northeast should incorporate the existence of these two reservoirs, and simulate or at least parameterize the role of mixing between them in multiday smog events.

Acknowledgments. Funding for this work was provided by the Maryland Department of Environment (MDE) and the Mid-Atlantic/Northeast Visibility Union (MANE-VU). The authors would like to thank the Center for Ocean-Land-Atmosphere Studies (COLA), Institute of Global Environment and Society, Calverton, Maryland, for the use of Grid Analysis and Display System (GrADS). A special thanks for their support and contributions goes to George "Tad" Aburn, George Allen, Kevin Civerolo, Tom Downs, Daniel Kirk-Davidoff, Al Leston, Rich Poirot, Matt Seybold, Gopal Sistla, and Jeff Underhill.

\section{REFERENCES}

Anderson, T. L., and J. A. Ogren, 1998: Determining aerosol radiative properties using the TSI 3563 Integrating Nephelometer. Aerosol Sci. Technol., 29, 57-69.

_ - and Coauthors, 1996: Performance characteristics of a highsensitivity, three-wavelength, total scatter/backscatter nephelometer. J. Atmos. Oceanic Technol., 13, 967-986.

— D. S. Covert, J. D. Wheeler, J. M. Harris, K. D. Perry, B. E. Trost, and D. J. Jaffe, 1999: Aerosol backscatter fraction and single scattering albedo: Measured values and uncertainties at a coastal station in the Pacific NW. J. Geophys. Res., 104, $26793-$ 26807.

, S. J. Masonis, D. S. Covert, N. C. Ahlquist, S. G. Howell, A. D. Clarke, and C. S. McNaughton, 2003: Variability of aerosol optical properties derived from in situ aircraft measurements during ACE-Asia. J. Geophys. Res., 108, 8647, doi: 10.1029/ 2002JD003247.

Andreae, M. O., and P. J. Crutzen, 1997: Atmospheric aerosols: Biogeochemical sources and role in atmospheric chemistry. Science, 276, 1052-1058

Banta, R. M., and Coauthors, 1998: Daytime buildup and nighttime transport of urban ozone in the boundary layer during a stagnation episode. J. Geophys. Res., 103, 22 519-22 544.

Baumann, K., and Coauthors, 2000: Ozone production and transport near Nashville, Tennessee: Results from the 1994 study at New Hendersonville. J. Geophys. Res., 105, 9137-9153.

Benjamin, S. G., J. M. Brown, K. J. Brundage, B. E. Schwartz, T. G. Smirnova, and T. L. Smith, 1998: The operational RUC-2. Preprints, 16th Conf. on Weather Analysis and Forecasting, Phoenix, AZ, Amer. Meteor. Soc., 249-252.

Bergstrom, R. W., P. B. Russell, and P. Hignett, 2002: Wavelength dependence of the absorption of black carbon particles: Predictions and results from the TARFOX experiment and implications for the aerosol single scattering albedo. J. Atmos. Sci., 59, 567577.

Berkowitz, C. M., and W. J. Shaw, 1997: Airborne measurements of boundary layer chemistry during the southern oxidant study: A case study. J. Geophys. Res., 102, 12 795-12 804.

Bodhaine, B. A., 1995: Aerosol absorption measurements at Barrow, Mauna Loa, and the South Pole. J. Geophys. Res., 100, 8967 8975.

Bond, T. C., T. L. Anderson, and D. Campbell, 1999: Calibration and intercomparison of filter-based measurements of visible light absorption by aerosols. Aerosol Sci. Technol., 30, 582-600.

Chen, L. W. A., 2002: Urban fine particulate matter: Chemical composition and possible origins. Ph.D. dissertation, University of Maryland, $194 \mathrm{pp}$.

— B. B. Doddridge, R. R. Dickerson, J. C. Chow, P. K. Mueller, J. Quinn, and W. A. Butler, 2001: Seasonal variations in elemental carbon aerosol, carbon monoxide, and sulfur dioxide: Implications for sources. Geophys. Res. Lett., 28, 1711-1714.

$-,-\ldots,-\ldots$, and R. C. Henry, 2002: Origins of fine aerosol mass in the Baltimore-Washington Corridor: Implications from observations, factor analysis, and ensemble back trajectories. Atmos. Environ., 36, 4541-4554.

Chin, M., D. J. Jacob, J. W. Munger, D. D. Parrish, and B. G. Doddridge, 1994: Relationship of ozone and carbon monoxide over North America. J. Geophys. Res., 99, 14 565-14 573.

Chung, S. H., and J. H. Seinfeld, 2002: Global distribution and climate forcing of Carbonaceous aerosols. J. Geophys. Res., 107, 4407, doi:10.1029/2001JD001397.

Civerolo, K. L., H. Mao, and S. T. Rao, 2003: The airshed for ozone and fine particulate pollution in the eastern United States. Pure Appl. Geophys., 160, 81-105.

COESA, 1976: U.S. Standard Atmosphere, 1976. U.S. Government Printing Office, $227 \mathrm{pp}$.

Crutzen, P. J., 1971: Ozone production rates in an oxygen-hydrogennitrogen oxide atmosphere. J. Geophys. Res., 76, 7311-7327.

Daum, P. H., L. I. Kleinman, L. Newman, W. T. Luke, J. WeinsteinLloyd, C. M. Berkowitz, and K. M. Busness, 1996: Chemical and physical properties of plumes of anthropogenic pollutants transported over the North Atlantic during the North Atlantic Regional Experiment. J. Geophys. Res., 101, 29 029-29 042.

Dickerson, R. R., and A. C. Delaney, 1988: Modification of a commercial gas filter correlation $\mathrm{CO}$ detector for increased sensitivity. J. Atmos. Oceanic Technol., 5, 424-431.

— - B. G. Doddridge, P. Kelley, and K. P. Rhoads, 1995: Largescale pollution of the atmosphere over the remote Atlantic Ocean: Evidence from Bermuda. J. Geophys. Res., 100, 89458952.

— , S. Kondragunta, G. Stenchickov, K. L. Civerolo, B. G. Doddridge, and B. N. Holben, 1997: The impact of aerosols on solar ultraviolet radiation and photochemical smog. Science, 278, $827-830$. 
Doddridge, B. G., 1995: Rapporteur's report of the Working Session on Measurement Techniques and Standards. WMO, 8-11.

Draxler, R. R., and G. D. Rolph, cited 2003: HYSPLIT (HYbrid Single-Particle Lagrangian Integrated Trajectory) Model access via NOAA ARL READY Website. NOAA Air Resources Laboratory, Silver Spring, MD. [Available online at http:// www.arl.noaa.gov/ready/hysplity.html.]

Dubovik, O., B. N. Holben, T. F. Eck, A. Smirnov, Y. J. Kaufman, M. D. King, D. Tanre, and I. Slutsker, 2002: Variability of absorption and optical properties of key aerosol types observed in worldwide locations. J. Atmos. Sci., 59, 590-608.

Fast, J. D., R. A. Zaveri, R. X. Bian, E. G. Chapman, and R. C. Easter, 2002: Effect of regional scale transport on oxidants in the vicinity of Philadelphia during the 1999 NE-OPS field campaign. J. Geophys. Res., 107, 4307, doi: 10.1029/2001JD000980.

Hartley, W. S., P. V. Hobbs, J. L. Ross, P. B. Russell, and J. M Livingston, 2000: Properties of aerosols aloft relevant to direct radiative forcing off the Mid-Atlantic coast of the United States. J. Geophys. Res., 105, 9859-9885.

Haywood, J., and O. Boucher, 2000: Estimates of the direct and indirect radiative forcing due to tropospheric aerosols: A review. Geophys. Rev., 38, 513-543.

Hegg, D. A., J. Livingston, P. V. Hobbs, T. Novakov, and P. Russell, 1997: Chemical apportionment of aerosol column optical depth off the Mid-Atlantic coast of the United States. J. Geophys. Res. 102, 25 293-25303.

Hoffman, M. R., 1986: On the kinetics and mechanism of oxidation of aquated sulfur-dioxide by ozone. Atmos. Environ., 20, 11451154.

Jacobson, M. Z., 2000: A physically-based treatment of elemental carbon optics: Implications for global direct forcing of aerosols Geophys. Res. Lett., 27, 217-220.

— 2001: Strong radiative heating due to the mixing state of black carbon in atmospheric aerosols. Nature, 409, 695-697.

Kleinman, L. I., and Coauthors, 2000: Ozone production in the New York City urban plume. J. Geophys. Res., 105, 14 495-14 511

Lesins, G., P. Chylek, and U. Lohmann, 2002: A study of internal and external mixing scenarios and its effect on aerosol optical properties and direct radiative forcing. J. Geophys. Res., 107, 4094, doi:10.1029/2001JD000973.

Luke, W. T., 1997: Evaluation of a commercial pulsed fluorescence detector for the measurement of low-level $\mathrm{SO}_{2}$ concentrations during the Gas-Phase Sulfur Intercomparison Experiment. $J$. Geophys. Res., 102, $16255-16265$.

_ T. B. Watson, K. J. Olszyna, R. L. Gunter, R. T. McMillen, D. L. Wellman, and S. W. Wilkison, 1998: A comparison of airborne and surface trace gas measurements during the Southern Oxidants Study (SOS). J. Geophys. Res., 103, 22 317-22 337.

Malm, W. C., 1992: Characteristics and origins of haze in the continental United States. Earth-Sci. Rev., 33, 1-36.

Menon, S., J. Hansen, L. Nazarenko, and Y. F. Luo, 2002: Climate effects of black carbon aerosols in China and India. Science, 297, 2250-2253.

Novakov, T., D. A. Hegg, and P. V. Hobbs, 1997: Airborne measurements of carbonaceous aerosols on the East Coast of the United States. J. Geophys. Res., 102, 30 023-30 030.

Novelli, P. C., and Coauthors, 1998: An internally constistent set of globally distributed atmospheric carbon monoxide mixing ratios developed using results from an intercomparison of measurements. J. Geophys. Res., 103, 19 285-19 293.

Pagnotti, V., 1987: A mesoscale meteorological feature associated with high ozone concentrations in the northeastern United States. J. Air Pollut. Control Assoc., 37, 720-722.

Parish, T. R., A. R. Rodi, and R. D. Clark, 1988: A case study of the summertime Great Plains low level jet. Mon. Wea. Rev., 116, 94-105.

Park, R. J., G. L. Stenchikov, K. E. Pickering, R. R. Dickerson, D. J. Allen, and S. Kondragunta, 2001: Regional air pollution and its radiative forcing: Studies with a single-column chemical and radiation transport model. J. Geophys. Res., 106, 28 751-28 770.

Rao, S. T., J. Y. Ku, S. Berman, K. Zhang, and H. Mao, 2003: Summertime characteristics of the atmospheric boundary layer and relationships to ozone levels over the eastern United States. Pure Appl. Geophys., 160, 21-55.

Remer, L. A., S. Gasso, D. A. Hegg, Y. J. Kaufmann, and B. N. Holben, 1997: Urban/industrial aerosol: Ground based sun/sky radiometer and airborne in situ measurements. J. Geophys. Res., 102, $16849-16859$

Ryan, W. F., and Coauthors, 1998: Pollutant transport during a regional $\mathrm{O}_{3}$ episode in the Mid-Atlantic states. J. Air Waste Manage. Assoc., 48, 786-797.

Seaman, N. L., and S. A. Michelson, 2000: Mesoscale meteorological structure of a high-ozone episode during the 1995 NARSTONortheast study. J. Appl. Meteor., 39, 384-398.

Sistla, G., W. Hao, J. Y. Ku, G. Kallos, K. Zhang, H. Mao, and S. T. Rao, 2001: An operational evaluation of two regional-scale ozone air quality modeling systems over the eastern United States. Bull. Amer. Meteor. Soc., 82, 945-964.

Stehr, J. W., R. R. Dickerson, K. A. Hallock-Waters, B. G. Doddridge, and D. Kirk, 2000: Observations of $\mathrm{NO}_{\mathrm{y}}, \mathrm{CO}$, and $\mathrm{SO}_{2}$ and the origin of reactive nitrogen in the eastern United States. J. Geophys. Res., 105, 3553-3563.

Vukovitch, F. M., 1995: Regional scale boundary layer ozone variations in the eastern United States and their association with meteorological variations. Atmos. Environ., 29, 2259-2273.

Zelenka, M. P., 1997: An analysis of the meteorological parameters affecting ambient concentrations of acid aerosols in Uniontown, Pennsylvania. Atmos. Environ., 31, 869-878.

Zhang, J., and S. T. Rao, 1999: The role of vertical mixing in the temporal evolution of ground-level ozone concentrations. $J$. Appl. Meteor., 38, 1674-1691.

, — , and S. M. Daggupaty, 1998: Meteorological processes and ozone exceedances in the northeastern United States during the 12-16 July 1995 episode. J. Appl. Meteor., 37, 776-789. 